Marquette University

e-Publications@Marquette

Physics Faculty Research and Publications

Physics, Department of

$11-1-2010$

\title{
Low Temperature Photo-oxidation of Chloroperoxidase Compound II
}

Xinting Yuan

University of Illinois at Chicago

Xin Sheng

University of Illinois at Chicago

John A. Horner

University of Illinois at Chicago

Brian Bennett

Marquette University, brian.bennett@marquette.edu

Leslie W.-M. Fung

University of Illinois at Chicago

See next page for additional authors

NOTICE: this is the author's version of a work that was accepted for publication in Journal of Inorganic Biochemistry. Changes resulting from the publishing process, such as peer review, editing, corrections, structural formatting, and other quality control mechanisms may not be reflected in this document. Changes may have been made to this work since it was submitted for publication. A definitive version was subsequently published in Journal of Inorganic Biochemistry, Vol. 104, No. 11 (November 2010): 1156-1163. DOI. (C) 2010 Elsevier. Used with permission.

Brian Bennett was affiliated with the Medical College of Wisconsin at the time of publication. 
Authors

Xinting Yuan, Xin Sheng, John A. Horner, Brian Bennett, Leslie W. -M. Fung, and Martin Newcomb 


\title{
Low Temperature Photo-Oxidation of Chloroperoxidase Compound II
}

\author{
Xinting Yuana ${ }^{a}$, Xin Sheng ${ }^{a}$, John H. Hornera ${ }^{\text {, Brian Bennett }}{ }^{b,}{ }^{*}$, Leslie W.-M. Fung ${ }^{a,}{ }^{*}$, and \\ Martin Newcomb ${ }^{a}$, \\ aDepartment of Chemistry, University of Illinois at Chicago, 845 West Taylor St., Chicago, Illinois \\ 60607 \\ bDepartment of Biophysics, Medical College of Wisconsin, 8701 Watertown Plank Road, Milwaukee, \\ Wisconsin 53226
}

\section{Abstract}

Oxidation of the heme-thiolate enzyme chloroperoxidase (CPO) from Caldariomyces fumago with peroxynitrite (PN) gave the Compound II intermediate, which was photo-oxidized with $365 \mathrm{~nm}$ light to give a reactive oxidizing species. Cryo-solvents at $\mathrm{pH} \approx 6$ were employed, and reactions were conducted at temperatures as low as $-50^{\circ} \mathrm{C}$. The activity of $\mathrm{CPO}$ as evaluated by the chlorodimedone assay was unaltered by treatment with PN or by production of the oxidizing transient and subsequent reaction with styrene. EPR spectra at $77 \mathrm{~K}$ gave the amount of ferric protein at each stage in the reaction sequence. The PN oxidation step gave a 6:1 mixture of Compound II and ferric $\mathrm{CPO}$, the photolysis step gave an approximate 1:1 mixture of active oxidant and ferric $\mathrm{CPO}$, and the final mixture after reaction with excess styrene contained ferric $\mathrm{CPO}$ in $80 \%$ yield. In single turnover reactions at $-50{ }^{\circ} \mathrm{C}$, styrene was oxidized to styrene oxide in high yield. Kinetic studies of styrene oxidation at $-50{ }^{\circ} \mathrm{C}$ displayed saturation kinetics with an equilibrium constant for formation of the complex of $K_{\text {bind }}=3.8 \times 10^{4} \mathrm{M}^{-1}$ and an oxidation rate constant of $k_{\mathrm{ox}}=0.30 \mathrm{~s}^{-1}$. UV-visible spectra of mixtures formed in the photo-oxidation sequence at ca. $-50{ }^{\circ} \mathrm{C}$ did not contain the signature Qband absorbance at $690 \mathrm{~nm}$ ascribed to CPO Compound I prepared by chemical oxidation of the enzyme, indicating that different species were formed in the chemical oxidation and the photooxidation sequence.

\section{Keywords}

chloroperoxidase; Compound I; UV-visible spectrum; EPR spectrum; kinetics; oxidation

\section{Introduction}

The cytochrome P450 (CYP or P450) enzymes are heme-containing enzymes with thiolate from protein cysteine as the fifth ligand to iron [1,2]. The predominant role of P450s in nature is to serve as oxidation catalysts, and these enzymes have been modeled by simple porphyrin-

\section{(C) 2010 Elsevier Inc. All rights reserved.}

Corresponding author: Prof. Martin Newcomb, Department of Chemistry, University of Illinois at Chicago, 845 W. Taylor St., Chicago, IL 60607, men@uic.edu, telephone: +1 312-413-2106, fax: +1 312-996-0431.

Publisher's Disclaimer: This is a PDF file of an unedited manuscript that has been accepted for publication. As a service to our customers we are providing this early version of the manuscript. The manuscript will undergo copyediting, typesetting, and review of the resulting proof before it is published in its final citable form. Please note that during the production process errors may be discovered which could affect the content, and all legal disclaimers that apply to the journal pertain. 
and salen-iron complexes that are efficient catalysts in oxidations employing peroxy compounds as sacrificial oxidants $[3,4]$. In humans, the P450s are the primary enzymes involved in metabolism of drugs, pro-drugs, and other xenobiotics, and their over-expression is related to diseases including cancer and liver disease [5]. Despite considerable interest in $\mathrm{P} 450$ s from pharmacological and medicinal perspectives and the fact that more than 11,000 members of this family of enzymes are already known [6], the oxidizing transients formed in $\mathrm{P} 450$ s are poorly characterized due in part to their high reactivities.

The high-valent iron-oxo complexes formed in peroxidase and catalase enzymes are iron(IV)oxo porphyrin radical cations [7] termed Compounds I, and for many years similar intermediates have been assumed to be the active oxidants in P450s. An especially important peroxidase enzyme for modeling $\mathrm{P} 450$ s has been chloroperoxidase (CPO) from Caldariomyces fumago [8], which, similar to P450s, contains a cysteine thiolate ligand to iron instead of the histidine nitrogen ligand in typical peroxidases. Upon reaction with hydrogen peroxide or peroxy acids, CPO forms a Compound I transient [9] that is relatively stable $\left(t_{1 / 2} \approx 1 \mathrm{~s}\right.$ at $22^{\circ}$ $\mathrm{C}[10])$, and CPO Compound I has served as a surrogate for P450 Compounds I in various spectroscopic and kinetic studies. The UV-visible spectrum of CPO Compound I observed in acidic solutions at room temperature [9,11] resembles that of Compound I from catalase [7, 12] with a Soret band absorbance at $367 \mathrm{~nm}$ and a Q-band absorbance at $690 \mathrm{~nm}$, and it is commonly assumed that the UV-visible spectra of P450 Compounds I will resemble that of CPO Compound I [13].

P450 Compounds I generally have eluded preparation by fast mixing studies with chemical oxidants such as peroxy compounds, but an alternative entry to these transients was recently developed. Compound II transients, iron(IV)-oxo neutral porphyrin species, from horseradish peroxidase and a model compound were photo-oxidized to give Compounds I [14]. The method was extended to give P450 oxidants, but the UV-visible spectra of these transients deduced from laser flash photolysis difference spectra [15-17] did not resemble the reported spectrum of CPO Compound I. Thus, it is possible that the P450 oxidants formed in the photo-oxidation route could be different species than Compounds I formed in the chemical oxidation pathway.

CPO is known to react with PN to give the Compound II transient $[15,18,19]$, and preliminary results indicating that CPO Compound II was successfully photo-oxidized in LFP studies at room temperature were reported [15]. In the present work, we applied the photo-oxidation method for oxidation of CPO Compound II at low temperatures and essentially neutral $\mathrm{pH}$ in a cyro-solvent consisting of a 1:1 mixture of glycerol and buffer solution. A CPO oxidant was produced by this sequence and was characterized by EPR spectra at $77 \mathrm{~K}$, the products from its oxidation of styrene, the kinetics of its reaction with styrene at $-50{ }^{\circ} \mathrm{C}$, and $\mathrm{UV}$-visible spectroscopy. Although the transient is a highly reactive oxidant, it is not identical to the Compound I species formed by chemical oxidation of CPO.

\section{Materials and Methods}

\subsection{Chloroperoxidase (CPO) from Caldariomyces fumago}

was prepared from cultures of the fungus and purified by reported methods [20,21]. Crude $\mathrm{CPO}$ enzyme was stored at $-80^{\circ} \mathrm{C}$ and purified immediately before use to give enzyme with an $R Z$ value $>1.4$. The activity of CPO was assayed by the chlorodimedone method reported by Hager et al. [22].

\subsection{Photo-irradiation equipment}

The photo reactor was assembled in house. The reaction chamber was a jacketed cell holder mounted in a reaction cube (ca. $8 \mathrm{~cm}$ sides) that could be flushed with nitrogen. The cell holder 
was cooled by circulating methanol from a cryostat, and the temperature was measured with a thermocouple placed inside the cell holder. The reaction box contained ports for fiber optics cables, and UV-visible spectra were obtained via fiber optics with an Ocean Optics USB-4000 spectrometer. Light was provided by an EFOS Novacure 2000 photolysis unit, which was calibrated to deliver precise pulses in units of time as short as $0.1 \mathrm{~s}$. Light from a mercury bulb was filtered through a $365 \pm 5 \mathrm{~nm}$ cut-off filter. Light was delivered through a gel optics waveguide mounted in a port orthogonal to those for the fiber optics cables. Either polymethyl methacrylate UV-visible spectroscopy cells or quartz EPR tubes were mounted in the cell holder for the preparation of samples.

\subsection{Photo-Oxidation of CPO Compound II}

In a typical experiment, a $200 \mu \mathrm{L}$ solution of $5 \mu \mathrm{M}$ CPO in $100 \mathrm{mM}$ phosphate buffer (pH 4.8) containing $50 \%$ by volume glycerol was cooled to ca. $-15^{\circ} \mathrm{C}$ in a microcell with UV-visible monitoring as previously described [23]. A basic solution (ca. $2 \mu \mathrm{L}$ ) of $35 \mathrm{mM}$ sodium peroxynitrite $(\mathrm{PN})$ solution [24] was added, giving a mixture with $\mathrm{pH} \sim 6$. When $\mathrm{PN}$ decay was complete as judged by the loss of signal at $308 \mathrm{~nm}$ from $\mathrm{PN}$, the solution was cooled to $-50{ }^{\circ} \mathrm{C}$. The solution was irradiated with $5.0 \mathrm{~J}$ of $365 \mathrm{~nm}$ light delivered in $1.0 \mathrm{~s}$, which converted Compound II in high yield as judged by the decrease in at $\lambda_{\max }$ of the Soret band signal for Compound II. Spectral results were deconvoluted with Pro-K software (Applied Photophysics).

\subsection{EPR Spectra}

Samples of CPO Compound II were photolyzed in quartz EPR tubes in the above described reactor by a method similar to that described above for preparation in UV cells except that all concentrations were increased. Thus, approximately $100 \mu \mathrm{L}$ of a $200 \mu \mathrm{M}$ CPO solution in a 1:1 (v:v) mixture of glycerol and $100 \mathrm{mM}$ phosphate buffer (pH 4.0) in a standard $4.5 \mathrm{~mm}$ EPR tube was held at $-10^{\circ} \mathrm{C}$. The mixture was treated with $10 \mu \mathrm{L}$ of $100 \mathrm{mM}$ of basic PN solution [24], which raised the final $\mathrm{pH}$ to ca. 6. After decay of excess PN was complete, as judged by monitoring the PN signal at $308 \mathrm{~nm}$, the samples were cooled to $-45^{\circ} \mathrm{C}$ and irradiated with ca. $25 \mathrm{~J}$ of $365 \mathrm{~nm}$ light delivered in $5 \mathrm{~s}$, and the reaction progress was monitored by observing the Q-bands in the 500-700 nm range. Samples were cooled in liquid nitrogen approximately $1 \mathrm{~s}$ after completion of the irradiation step. EPR spectra were recorded at $77 \mathrm{~K}$ on a Varian E109 spectrometer equipped with a TM 102 cavity at $9.41 \mathrm{GHz}$ and a liquid nitrogen Dewar flask. The following instrument parameters were used: scan width $=2200-4200 \mathrm{G}$, power $=1$ $\mathrm{mW}$, modulation amplitude $=20 \mathrm{G}$, and gain $=2.5 \times 10^{3}$. Spectra typically were obtained with 4 scans.

EPR spectra also were recorded at $10 \mathrm{~K}$ and $9.63 \mathrm{GHz}$ on a Bruker EleXsys spectrometer equipped with an ER4116DM cavity, a $90 \mathrm{~dB}$ X-band bridge with integral microwave counter, and an Oxford ESR900 helium flow cryostat and ITC502 temperature controller. First derivative spectra were recorded at $1 \mathrm{~mW}$ microwave power, with $2000-6000 \mathrm{G}$ field scan width, 4096 field sampling points, and $10 \mathrm{G}$ field modulation amplitude at $100 \mathrm{kHz}$. Other parameters were chosen such that modulation amplitude limited resolution. Rapid-passage and saturation effects were evident at $80 \mathrm{~mW}$ and rapid-passage pseudo absorption spectra were obtained using second-harmonic phase sensitive detection $90^{\circ}$ out-of-phase with the field modulation.

\subsection{Kinetic Studies}

Samples were prepared as described above for spectral studies with the exception that styrene at the desired concentration was added to the sample before the PN treatment. Following preparation of Compound II at ca. $-15^{\circ} \mathrm{C}$ and decay of excess PN, the samples were cooled to $-50{ }^{\circ} \mathrm{C}$ and irradiated with $5 \mathrm{~J}$ of $365 \mathrm{~nm}$ light. Following the photolysis step, the signal at 
$426 \mathrm{~nm}$ was monitored. As reported for similar studies $[23,25]$, the signal growth was described by a double exponential function where the major exponential term increased with the concentration of styrene, and the minor exponential term was independent of styrene concentration. The styrene concentration-dependent kinetic values were analyzed by nonlinear regression analysis according to the function in Eq. 1 in the text. Data analyses were performed with Sigma-Plot software.

\subsection{Product Identification and Quantification}

A solution containing CPO ( $3 \mathrm{nmol})$ and styrene $(0.2 \mu \mathrm{mol})$ in $200 \mu \mathrm{L}$ of a $1: 1$ (v:v) mixture of glycerol and $100 \mathrm{mM}$ phosphate buffer $(\mathrm{pH} 4.8)$ was cooled to ca. $-15^{\circ} \mathrm{C}$, and a basic aqueous solution of $0.21 \mu \mathrm{mol}$ of sodium peroxynitrite (PN) $(6 \mu \mathrm{L}$ volume) was added. When $\mathrm{PN}$ decay was complete as determined by UV-visible spectroscopy, the solution was cooled to $-50{ }^{\circ} \mathrm{C}$. The mixture was irradiated with $15 \mathrm{~J}$ of $365 \mathrm{~nm}$ light delivered in ca. $3.0 \mathrm{~s}$. After warming, the reaction mixture was extracted into methylene chloride, and the organic layer was washed with saturated aqueous sodium chloride solution and dried $\left(\mathrm{MgSO}_{4}\right)$. An internal standard of 1-phenylethanol was added, and the mixture was analyzed by GC and GC-mass spectrometry. Styrene oxide was the only significant product detected; it was identified by comparison of its GC retention time and mass spectrum to those of an authentic commercial sample (Aldrich). The GC yield of styrene oxide was $53 \%$ based on CPO initially present in the mixture as determined by comparison to the internal standard using predetermined response factors. In control experiments, no styrene oxide was formed when the reaction was run as described above but without the irradiation step nor when the reaction was run as above but the PN was omitted.

\section{Results}

\subsection{Photo-oxidation of CPO Compound II}

The reaction sequence established for horseradish peroxidase (HRP) is shown in Scheme 1 [14]. The ferric resting enzyme was oxidized to a Compound II intermediate by treatment with peroxynitrite (PN), and subsequent photolysis of this species gave Compound I. Heme enzyme Compound II intermediates are iron(IV)-oxo species, but we show an iron(IV) hydroxide structure in Scheme I because this type of structure was indicated by long Fe-O bonds in the extended X-ray absorption fine structure (EXAFS) spectra of both CPO Compound II [26] and Compound II from the P450 enzyme CYP119 [27]. HRP Compound II photolysis gave the known Compound I species [14], and the expectation was that the same reaction sequence would be found for CPO.

The CPO Compound II species was formed rapidly upon mixing PN solution with CPO. The UV-visible spectrum of CPO Compound II from the PN oxidation reaction $[15,18,19]$ is the same as that of CPO Compound II produced by reaction of $\mathrm{CPO}$ with hydrogen peroxide and ascorbate [28]. CPO Compound II decomposed rapidly at room temperature $[15,18,19]$, but its lifetime was extended considerably when it was produced at $-15^{\circ} \mathrm{C}$ in this work.

In order to quantify conversions in the PN oxidation and photo-oxidation steps, we used EPR spectroscopy. Whereas complete characterization of the photo-oxidation product requires low temperature EPR spectroscopy $[29,30]$, spectra recorded at $77 \mathrm{~K}$ are readily obtained and provide a convenient measure of the amount of CPO resting enzyme present in the samples at each point in the reaction as judged from the low-spin state signals of the ferric protein. Ferric CPO can exist in both high-spin and low-spin states, but low temperature EPR spectra of samples prepared in acetate buffer at $\mathrm{pH} 5.2$ and in phosphate buffer at $\mathrm{pH} 8.2$ showed signals mainly from the low spin form of CPO [31]. In fact, as discussed later, the low-spin form is produced quickly from the high-spin form at $-45^{\circ} \mathrm{C}$ in the cryo-solvent we used. 
For the EPR spectroscopy studies, the CPO concentrations were $200 \mu \mathrm{M}$. This concentration precluded observations of the strongly absorbing Soret bands in the UV-visible spectra, but reaction progress could be monitored by observing the Q-bands (or visible bands). The CPO Compound II samples were prepared in EPR tubes at $-15^{\circ} \mathrm{C}$ by addition of excess PN solution [24] to a solution of CPO in a cryo-solvent consisting of a 1:1 mixture (v:v) of glycerol and $100 \mathrm{mM}$ phosphate buffer initially at $\mathrm{pH}=4.0$. When excess $\mathrm{PN}$ had decayed, the reaction mixture was cooled to $-45^{\circ} \mathrm{C}$ and irradiated with $25 \mathrm{~J}$ of $365 \mathrm{~nm}$ light delivered in ca. $5 \mathrm{~s}$, after which point no further changes in the Q-band absorbances were apparent. In a similar reaction sequence, $0.1 \mathrm{mM}$ styrene was present in the reaction mixture. At the various steps in the reaction sequence, samples were cooled in liquid nitrogen, and EPR spectra were obtained at $77 \mathrm{~K}$. Figure 1 shows a series of EPR spectra for the initial resting CPO, the mixture containing Compound II from reaction of the enzyme with $\mathrm{PN}$ at $-15^{\circ} \mathrm{C}$, the mixture obtained from photolysis of a mixture containing Compound II at $-45^{\circ} \mathrm{C}$, and the mixture obtained from photolysis of Compound II in the presence of styrene at $-45^{\circ} \mathrm{C}$. The sample of resting enzyme is $10 \%$ more concentrated than other samples due to the dilution when PN solution was added.

The initial samples of CPO resting enzyme showed three signals for the low spin ferric enzyme at $\mathrm{g}=1.81,2.23$, and 2.58 (lit: $\mathrm{g}=1.83,2.26$, and 2.61 [31]). In the sample containing Compound II, small absorbances from resting enzyme were observed, consistent with the expectation that the iron(IV)-oxo species $(S=1)$ is effectively EPR silent. Because all EPR spectra were obtained with the same instrument settings, we compared the integrals of the $\mathrm{g}=$ 2.23 signals to determine the conversions in each sample. For the Compound II sample, the integral of the $\mathrm{g}=2.23$ was $11 \%$ of that for the resting enzyme. Adjusting for $10 \%$ dilution upon addition of the PN solution, the sample containing Compound II was an 87:13 mixture of CPO Compound II and resting enzyme. We note that CPO Compound II is unstable, decomposing with a half-life of about $0.2 \mathrm{~s}$ at room temperature after PN is depleted [15], and it is possible that a portion of the $\mathrm{CPO}$ detected was regenerated from Compound II during the period of mixing at $-15^{\circ} \mathrm{C}$ before cooling to $77 \mathrm{~K}$.

The irradiation step gave a sample with EPR spectrum C in Figure 1. In this sample, changes in the Q-band signals in the UV-visible spectrum were complete at the end of the irradiation period. The $77 \mathrm{~K}$ EPR spectra displayed the three signals from resting enzyme, and the integral of the $\mathrm{g}=2.23$ signal was $43 \%$ in comparison to that from the resting enzyme. After correction for dilution, one concludes that the sample was a mixture of 52\% undetectable species and $48 \%$ resting enzyme. In addition to the three signals from resting enzyme, the spectra contained absorbances in the range of $\mathrm{g}=2$ as shown in Figure 1. The sample before irradiation contained $13 \%$ of resting $\mathrm{CPO}$, and an additional ca. $35 \%$ of resting $\mathrm{CPO}$ was produced in the photolysis. The majority of the $52 \%$ of "EPR undectable" enzyme is ascribed to an oxidized product from the Compound II because the Q-bands observed in the UV-visible spectrum were considerably altered from those of Compound II. Accordingly, the photolysis step converted Compound II to an approximately 2:1 mixture of an oxidizing species and CPO resting enzyme.

The EPR spectrum D in Figure 1 is for a mixture produced when CPO Compound II was generated at $-45^{\circ} \mathrm{C}$ as above but in the presence of $0.1 \mathrm{mM}$ styrene, and the resulting mixture was held at $-45^{\circ} \mathrm{C}$ for several seconds before being cooled in liquid nitrogen. As described in the kinetics section, the photo-generated CPO oxidant reacts rapidly with styrene at this concentration and temperature, and all of the oxidizing species should be converted back to resting enzyme under the conditions of this experiment. The EPR spectrum in Figure 1D shows strong signals from ferric protein. Using the integral of the $\mathrm{g}=2.23$ signal and adjusting for concentration differences between the spectra of the initial CPO and the final mixture, we estimate that $80 \%$ of CPO resting enzyme was present after the complete reaction sequence. 
Samples also were studied by EPR spectroscopy at $10 \mathrm{~K}$. The $10 \mathrm{~K}$ derivative spectra were essentially indistinguishable from the $77 \mathrm{~K}$ spectra, although the rapid-passage pseudoabsorption spectra indicated significant intensity in the high- and low-field wings of the lowspin ferric signal from the photo-oxidized samples that was not present in the signal from the resting enzyme sample. From these spectra, the estimated amounts of ferric protein present from integration values were 100\% (resting enzyme standard), 30\% (Compound II sample), and $56 \%$ (photo-oxidized sample). These values were expected to be less precise measures of the ferric protein because broad high-spin signals will be integrated in the $10 \mathrm{~K}$ spectra, whereas they were saturated in the $77 \mathrm{~K}$ spectra. Nonetheless, the values are in reasonable agreement with those from the $77 \mathrm{~K}$ spectra.

A complete analysis of the $10 \mathrm{~K} \mathrm{EPR}$ spectra will include comparisons to spectra from similarly oxidized P450 enzymes and is beyond the scope of this work. We note, however, that the predominant high-spin signal from resting enzyme with resonances at $\mathrm{g}^{\prime}=7.5$ and 4.3 [ $\mathrm{g}(\mathrm{real})$ $=2.0, S=5 / 2, \mathrm{Ms}=1 / 2, \mathrm{E} / \mathrm{D}=0.07]$ loses $\sim 65 \%$ intensity in the photo-oxidized samples, and is replaced by a complex signal, with an asymmetrically broadened resonance at $\mathrm{g}^{\prime}=6.1$, that is likely due to an Ms $=1 / 2$ signal exhibiting significant strain in the rhombic zero-field splitting parameter E. This latter signal was either not reported [29,32] or not evident from the low temperature (rapid-passage) spectra [30] in published studies of CPO Compound I prepared by peroxyacetic acid oxidations of acidic solutions.

The species formed in the photo-oxidation route was demonstrated to be an oxidant of styrene. When a sample of CPO Compound II containing excess styrene photolyzed at $-50{ }^{\circ} \mathrm{C}, \mathrm{GC}$ and GC-mass spectral analysis of the products showed the production of styrene oxide in 53\% yield based on the initial amount of CPO present. This yield is effectively quantitative given that the EPR analysis of a similar sample indicated that the species generated by photo-oxidation was formed in 52\% yield relative to the total CPO. Control reactions established that no styrene oxide was formed when either PN or light was omitted from the reaction sequence.

In order to ensure that $\mathrm{CPO}$ survived the PN and photo-oxidation sequence with little or no degradation, we employed the chlorodimedone assay of CPO developed by Hager et al. [22]. In this method, CPO is added to a mixture containing hydrogen peroxide, potassium chloride, and chlorodimedone. $\mathrm{CPO}$ oxidizes the chloride to hypochlorite, which chlorinates chlorodimedone to give dichlorodimedone, and the loss of the absorbance from chlorodimedone at $278 \mathrm{~nm}$ is monitored spectroscopically. The rate of loss of chlorodimedone is directly proportional to the concentration of CPO.

The results of chlorodimedone assay studies are listed in Table 1. Samples of CPO were prepared and analyzed before reactions (samples 1a and 2a), after reaction at $-15{ }^{\circ} \mathrm{C}$ with 65 equivalents of PN (sample 1b) or 650 equivalents of PN (sample 1c), and after reaction with $\mathrm{PN}$ at $-15^{\circ} \mathrm{C}$ and photolysis in the presence of styrene at $-50^{\circ} \mathrm{C}$ (sample $2 \mathrm{~b}$ ). Note that samples $1 \mathrm{a}, 1 \mathrm{~b}$, and $1 \mathrm{c}$ are from one preparation of CPO, and samples $2 \mathrm{a}$ and $2 \mathrm{~b}$ are from a second preparation of CPO. There is no indication that CPO degraded appreciably when treated with 650 equivalents of PN, which is an order of magnitude more PN than employed in the photooxidation studies. In addition, the complete reaction sequence of Compound II production, photo-oxidation, and reaction with styrene did not result in an appreciable change in the $\mathrm{CPO}$ activity. We note that $\mathrm{CPO}$ reacted slowly in $\mathrm{pH} 8$ buffer to give, after ca. 30 minutes at room temperature, inactive protein as judged by the chlorodimedone assay (data not shown).

It is noteworthy that, in the above studies, $\mathrm{CPO}$ regenerated from the photo-oxidation sequence in the presence of styrene $-50^{\circ} \mathrm{C}$ was mainly in the low-spin form as determined by UV-visible spectroscopy [31]. Examples of the low-spin spectrum of CPO are shown later. Upon warming these samples to room temperature, the CPO returned to the high-spin form with a broad Soret 
band with $\lambda_{\max } \approx 398 \mathrm{~nm}$. In contrast, inactive $\mathrm{CPO}$ from the room temperature reaction at $\mathrm{pH}$ 8 had a spectrum that resembled that of the low-spin form even at room temperature.

\subsection{UV-visible spectra}

The UV-visible spectra of samples prepared by photo-oxidation at low temperatures were highly complex. The photo-oxidation step apparently produced three species, which we believe to be high-spin ferric enzyme, low-spin ferric enzyme, and the oxidizing species. At the low temperature of $-50{ }^{\circ} \mathrm{C}$, the high-spin $\mathrm{CPO}$ and oxidant reacted with different rate constants, apparently to give the same product, low-spin CPO. Thus, the observed spectra were superpositions of the spectra of at least three distinct species with similar dominant Soret band absorbances and which varied in concentration with at least two rate constants. One important point to emphasize at the outset is that, despite the complexity in the Soret band region, the region 650 to $720 \mathrm{~nm}$ was free of signals in all cases. The absence of a Q-band signal centered at $690 \mathrm{~nm}$ indicates that we did not produce the same transient as formed from reaction of CPO with peroxyacetic acid [9].

As a reference point for the spectral results, we show spectra from a sample of CPO in cryosolvent as the mixture was cooled from room temperature to $-45^{\circ} \mathrm{C}$ in Figure $2 \mathrm{~A}$. At room temperature, high-spin CPO is favored, and the spectrum shows a broad absorbance for the Soret band centered at $398 \mathrm{~nm}$. At $-45^{\circ} \mathrm{C}$, low-spin CPO is favored, and this species displays a Soret band with a sharp predominant peak centered at $424 \mathrm{~nm}$.

The close energy levels for the spin states of resting CPO result in a dynamic phenomenon that complicates spectral studies. Specifically, the resting CPO formed in the photolysis of Compound II at $-50{ }^{\circ} \mathrm{C}$ apparently is a mixture of low-spin and high-spin enzyme, and, at the low temperatures of our studies, the high-spin CPO relaxes to low-spin CPO with a rate constant similar to that for reactions of the oxidizing species. Examples are shown in Figure 2. Figure 2B shows initial spectra observed from photolysis of CPO Compound II at $-50{ }^{\circ} \mathrm{C}$ in the absence and presence of substrate styrene. In the absence of styrene, the spectrum changes with a rate constant of $k \approx 0.07 \mathrm{~s}^{-1}$, and deconvolution of this spectrum for the simple model of A $\rightarrow$ B gives the results in Figure 2C. The deconvoluted spectra appear to be those of high-spin $\mathrm{CPO}\left(\lambda_{\max } \approx 398 \mathrm{~nm}\right)$ and low-spin CPO $\left(\lambda_{\max } \approx 424 \mathrm{~nm}\right)$, and we believe that the observed rate constant is primarily that for the spin conversion of high-spin CPO to low-spin CPO. Under the conditions of no added substrate, the oxidizing species reacts too slowly at $-50{ }^{\circ} \mathrm{C}$ to make a dominant contribution to the kinetics on the time scale studied (see below).

When a reaction was conducted under similar conditions as above but with $0.5 \mathrm{mM}$ styrene present, the spectral changes were accelerated considerably, and deconvolution for the model of $\mathrm{A} \rightarrow \mathrm{B}$ gave the results in Figure 2D. The product (species B) in Figure 2D has a spectrum similar to that in Figure 2C, but the reactant (species A) does not. The new reactant appears to display absorbances both at longer and shorter wavelengths than high-spin CPO. We believe the new spectrum for reactant represents a superposition of spectra from the oxidizing species and high-spin resting $\mathrm{CPO}$, but we defer from simulating a three component reaction via global analysis because the solutions are not unique and we do not know if the oxidant reacts to give initially high-spin CPO, low-spin CPO, or a mixture of the two.

One important feature to note in the spectra from the photo-oxidation route is that we observed no absorbance at $\lambda=690 \mathrm{~nm}$ under any circumstances. As discussed later, the Q-band for CPO Compound I prepared by oxidation of CPO with peroxyacetic acid is centered at $690 \mathrm{~nm}$, and we should have seen this signal if we produced the same species in the photo-oxidation route as formed in the chemical oxidation route. 


\subsection{Kinetics of reactions at low temperatures}

Styrene was selected as a test substrate for studying the kinetics of oxidation at low temperatures. The kinetics of oxidation of styrene and a number of substituted styrenes by CPO Compound I at $22{ }^{\circ} \mathrm{C}$ were reported previously where CPO Compound I was produced by stopped-flow methods at room temperature [10], and styrene oxidations at low temperatures by photo-generated oxidants from the cytochrome P450 enzymes CYP119 and CYP102A1 heme domain were previously studied in detail [23]. As noted above, styrene was found to be oxidized to styrene oxide in high yield by the CPO oxidant.

Kinetic studies were performed in a manner similar to those previously reported for oxidations by P450 oxidants at low temperatures [23]. Samples of CPO Compound II were prepared by addition of PN solution at ca. $-15^{\circ} \mathrm{C}$ and further cooled to the desired reaction temperature. The samples were photolyzed with $5 \mathrm{~J}$ of $365 \mathrm{~nm}$ light delivered in $1 \mathrm{~s}$, and the reaction mixtures were monitored by UV-visible spectroscopy. When desired, styrene was present in the original reaction mixture before the PN oxidation. Rate constants for the reactions were solved for the kinetic behavior at $425 \mathrm{~nm}, \lambda_{\max }$ for the low-spin CPO in the cryo-solvent as double exponential processes.

When the photo-oxidations were conducted at $-50{ }^{\circ} \mathrm{C}$, high-spin ferric $\mathrm{CPO}$ was produced in part, and this species relaxed to low-spin enzyme. An example of this behavior is shown in Figure 2 . The rate constant for this reaction was $k \approx 0.07 \mathrm{~s}^{-1}$ at $-50^{\circ} \mathrm{C}$, and similar rate constants were observed in the temperature range -40 to $-20^{\circ} \mathrm{C}$. Although the relaxation reaction was not studied in detail, the apparent small or absent temperature dependence for the relaxation reaction indicates that the process has a small or zero activation enthalpy and is limited mainly by the entropy of activation.

The oxidant formed by photolysis of CPO Compound II proved to be more reactive towards styrene than those from $\mathrm{P} 450$ enzymes. Kinetic studies at $-50{ }^{\circ} \mathrm{C}$ were possible, but reactions could not be followed at higher temperatures because they were too fast for the method, which is limited to reactions with first-order or pseudo-first-order rate constants of $k<1 \mathrm{~s}^{-1}$. With styrene present, the pseudo-first-order rate constant for reaction with styrene was taken to be the observed rate constant minus the background rate constant obtained in the absence of styrene. A plot of the rate constants at $-50{ }^{\circ} \mathrm{C}$ versus styrene concentration was a non-linear function of substrate concentration (Figure 3). Such behavior was found previously in P450 oxidations of styrene at low temperatures [23], and it indicates that the reaction involved saturation kinetics (Scheme 2), where rapid, reversible formation of a complex was followed by a rate-limiting oxidation step.

The kinetic results were analyzed according to $\mathrm{Eq} 1$, where $k_{\mathrm{obs}}$ is the observed rate constant, $k_{0}$ is the background rate constant for decay in the absence of styrene, $K_{\text {bind }}$ is the equilibrium constant for formation of the complex, $k_{\mathrm{OX}}$ is the first-order rate constant for reaction of the complex, and [styrene] is the concentration of substrate styrene. Non-linear regression analysis of the data gave $K_{\text {bind }}=(3.8 \pm 0.8) \times 10^{4} \mathrm{M}^{-1}$ and $k_{\mathrm{ox}}=(0.30 \pm 0.01) \mathrm{s}^{-1}$ (errors at $1 \sigma$ ), and these values were used to generate the fitting line shown in Figure 3.

$$
k_{\mathrm{obs}}-k_{0}=\left(k_{\mathrm{ox}} K_{\text {bind }}[\text { styrene }]\right) /\left(K_{\text {bind }}[\text { styrene }]+1\right)
$$

\section{Discussion}

\subsection{Photo-oxidation of CPO Compound II}

The combination of spectroscopies, product analysis, and kinetics demonstrates that a strong oxidant was prepared by the photo-oxidation route. The formation of CPO Compound II by 
reaction of the resting enzyme with peroxynitrite was reported by Ullrich and co-workers in $2000[18]$ and was subsequently studied by others $[15,19]$. The photo-oxidation reactions of the heme protein horseradish peroxidase and model Compounds II to give Compounds I were reported in 2005 [14], and preliminary spectroscopic evidence for photo-oxidation of CPO Compound II at room temperature employing laser flash photolysis methods also was reported [15]. From the EPR and product analysis results in the present study, we conclude that the photolysis gave an approximate 1:1 mixture of CPO oxidizing species and resting enzyme.

The EPR spectral studies at $77 \mathrm{~K}$ provide the most convincing evidence that a reaction sequence similar to that in Scheme 1 was obtained. Under the conditions of the EPR measurements, ferric CPO will be predominantly low-spin [31], and we used the integrals of the low-spin signal at $\mathrm{g}=2.23$ to determine the amount of ferric CPO in the mixtures. The EPR spectrum of the photo-oxidized sample indicates that approximately $50 \%$ of the ferric enzyme was present. Because some ferric protein was present in the Compound II sample, one concludes that about one-third of the ferric protein after photolysis was carried through from the initial PN oxidation reaction and the remainder was formed in the photolysis reaction or immediately afterwards. Details of the photo-reaction (or multiple reactions) that gives ferric protein is a subject of current study in our group, but it is noteworthy that preliminary results with P450 enzymes suggest that continued irradiation with $365 \mathrm{~nm}$ light does not degrade samples of the oxidizing species appreciably.

The UV-visible and EPR spectroscopic results for samples that were carried through the PN reaction and photo-oxidation in the presence of styrene combined with the chlorodimedone activity assays indicated that little CPO was destroyed in the reaction cycle. The UV-visible spectrum of cycled CPO at room temperature showed no discernable difference from the spectrum of fresh high-spin CPO, the EPR spectrum indicated that ca. $80 \%$ of the resting CPO was returned after the complete reaction cycle, and the activity assay studies provided no evidence for enzyme activity loss from treatment with a large excess of PN or by PN oxidation followed by photo-oxidation. Ullrich and co-workers reported that at $\mathrm{pH} \mathrm{7.4,} \mathrm{a} \mathrm{40-fold} \mathrm{excess}$ of PN nitrated on average 1.4 tyrosines per CPO molecule of the 11 tyrosines in the enzyme [33], and our excess of PN was about twice as great. Nonetheless, the tyrosines of CPO are on the surface of the enzyme, and it is not clear that their nitration should have an effect on CPO activity. Gebicka and Didik reported partial inactivation of CPO when the enzyme was incubated with PN at pH 5.1, but no change in activity when it was incubated with $\mathrm{PN}$ at $\mathrm{pH}$ 7.1 [19], and they concluded that nitration of CPO increases in low $\mathrm{pH}$ media as the catalytic decomposition reaction of PN increases [19]. Their observation of no change in activity at $\mathrm{pH}$ 7.1 is similar to the results of our chlorodimedone assays, which were conducted on samples with $\mathrm{pH} 6$.

\subsection{UV-visible spectra observed following photo-oxidation}

CPO is known to display complex UV-visible and EPR spectra as a function of temperature and $\mathrm{pH}$ due to equilibration of high-spin and low-spin states [31]. At room temperature in a pH 3.0 phosphate buffer, the Soret bands of CPO appear as a broad band centered at about 398 $\mathrm{nm}$ and ascribed to high-spin enzyme [34]. When the sample was diluted with $50 \%$ glycerol and cooled to $77 \mathrm{~K}$, the frozen solution showed the UV-visible spectrum of low-spin CPO with split Soret bands at $360 \mathrm{~nm}$ (minor) and $420 \mathrm{~nm}$ (major) and sharpened Q-band absorbances in the range 500-600 nm [31]. This spectral change is shown in Figure 2A for a sample that was cooling from room temperature to $-45^{\circ} \mathrm{C}$ in the same cyro-solvent as used in our other studies.

In the low temperature photolysis reactions, ferric CPO is generated, apparently in both the high-spin and low-spin form. The favored species is a function of the temperature of the study, and low-spin $\mathrm{CPO}$ is the predominant form at $-50{ }^{\circ} \mathrm{C}$, where kinetic studies were possible. The 
conversion of high-spin CPO to low-spin enzyme complicates the spectral analysis, and we do not believe we can generate a unique spectrum for the transient by deconvolution of the results we obtained. If the model is that the transient reacts to give both high-spin and low-spin CPO and high-spin CPO converts to low-spin enzyme, then the spectrum of transient obtained from global analysis would have a broad Soret band absorbance between 350 and $450 \mathrm{~nm}$. In the deconvoluted spectra in Figure 2D, the spectrum from this species would be superimposed on that from high-spin CPO to give the broadened reactant spectrum (relative to that in Figure 2C) with an apparent shoulder at long wavelength.

In any event, the UV-visible spectral results are surprising in that we did not observe a strong Q-band absorbance for CPO Compound I at $690 \mathrm{~nm}$ suggesting that the species generated in the photo-oxidation route is not be the same as that produced by chemical oxidation of ferric CPO by peroxy acids and hydrogen peroxide. Figure 4 shows a spectrum of CPO Compound I from chemical oxidation of the enzyme that is similar to that reported originally by Hager [9]. If this species were formed in 50\% yield in our photo-oxidation reactions, the $690 \mathrm{~nm}$ absorbance should have been apparent.

The origins of the differences between the spectrum we obtained here for the CPO oxidant from photo-oxidation and the spectrum from oxidation of CPO with peroxy acids are not obvious. One possibility is that an environment effect such as temperature, solvent, or $\mathrm{pH}$ might be important, but preliminary results suggest that none of these factors is causative. We treated $\mathrm{CPO}$ with peroxyacetic acid in the cryo-solvent we used for other studies, in a mixture at $\mathrm{pH}$ 8 , and at a reduced temperature (stopped-flow mixing at $2{ }^{\circ} \mathrm{C}$ ), and all of the spectra thus obtained resembled that obtained from $\mathrm{CPO}$ at room temperature in acidic media when it is oxidized with a peroxy acid [9]. Unfortunately, we cannot test directly for a temperature effect on the spectrum of CPO Compound I after it is produced by the photolysis route because the species is too unstable to permit a change in temperature after it is generated.

An obvious alternative to an environment effect resulting in different spectra for CPO Compound I produced by the two routes is that the two methods give species that are not the same. They could differ in their electronic states, which might be controlled by conformational effects, or they could differ in the identity of the organic radical (i.e. porphyrin radical cation versus amino acid residue radical cation). Subtle conformational changes are likely involved in the temperature-dependent shift from a favored low-spin state for CPO at low temperature to the favored high-spin state at room temperature. In regard to possibly different CPO Compound I spectra, it is noteworthy that the UV-visible spectra of horseradish peroxidase Compound I (HRP-I) and catalase Compound I (Cat-I), the two Compounds I originally described as porphyrin radical cations by Dolphin [7], are considerably different. Specifically, Cat-I has a broad Soret absorbance from 320 to $450 \mathrm{~nm}$ that appears to be an overlap of two similarly intense bands and a Q-band absorbance at about $660 \mathrm{~nm}$ [12], and the Cat-I spectrum is similar to that of CPO Compound I from chemical oxidation. The HRP-I spectrum has overlapping Soret bands at ca. $350 \mathrm{~nm}$ and $405 \mathrm{~nm}$ [35] and a broad Q-band absorbance from about 500 to $600 \mathrm{~nm}[35,36]$ (see Figure 4), and is unlike the spectrum of Cat-I. The EPR and electron nuclear double resonance (ENDOR) spectra of HRP-I and Cat-I also differ [37,38], and all of these differences might be ascribed to different electronic states for the two, although Fujii and co-workers recently concluded from ENDOR results that both HRP-I and Cat-I were in the same electronic state [39].

At this time, we can only speculate as to the origins of the differences between CPO oxidants formed by chemical oxidation or photo-oxidation. The Compound I species formed by chemical oxidation is a relatively stable species, reacting with a lifetime of about 1 second at room temperature [10], and it should have been observable if it were formed in the photooxidation pathway. The oxidant that is produced might differ from the conventional Compound 
I because the species are in different states or because the radical is on a different residue. Further studies of this intriguing question clearly are necessary.

\subsection{Kinetics of Styrene Oxidation}

The kinetic study of styrene oxidation demonstrates that a strong oxidant was produced by the photo-oxidation route. The background reaction at $-50{ }^{\circ} \mathrm{C}$ had a rate constant of $k \approx 0.07$ $\mathrm{s}^{-1}$. This reaction is mainly due to the state change from a portion of high-spin CPO formed in the photolysis to low-spin $\mathrm{CPO}$, which is favored at $-50{ }^{\circ} \mathrm{C}$. When styrene was present, the reaction rate increased appreciably in a concentration-dependent but non-linear fashion shown in Figure 2. Such non-steady state or saturation kinetic behavior is a hallmark of enzyme reactions where high concentrations of the reactive ensemble can accumulate due to preferential binding properties.

When saturation kinetic behavior is observed, one can extract more information from the kinetics than when steady-state conditions exist. The equilibrium constant for formation of the reactive ensemble ( $K_{\text {bind }}$ ) has units of $\mathrm{M}^{-1}$. This constant is similar to a Michaelis constant in enzyme kinetics, $K_{\mathrm{M}}$, which is presented in terms of dissociation and has units of M, but the binding constant cannot contain kinetic terms for dissociation of product (a possibility for $K_{\mathrm{M}}$ ) because we are following single turnover reactions. The first-order oxidation rate constant $k_{\mathrm{OX}}$ is more informative than a second-order rate constant, in part because it should not contain a large entropy of activation term $[23,25]$.

The oxidation of styrene by CPO Compound I at $22{ }^{\circ} \mathrm{C}$ displayed an apparent second-order rate constant of $k_{\text {app }}=6.1 \times 10^{4} \mathrm{M}^{-1} \mathrm{~s}^{-1}$ [10]. Apparent second-order rate constants are found when the reactive complex does not accumulate to significant concentrations, i.e. when steadystate conditions exist, and the apparent second-order rate constant is the product of the firstorder rate constant and the equilibrium binding constant $\left(k_{\mathrm{app}}=k_{\mathrm{ox}} K_{\text {bind }}\right)$. One can compare the kinetic value found in this work with the earlier study of styrene oxidation at room temperature if some approximations are made. If we estimate that the entropy of activation for styrene oxidation by CPO Compound I will be approximately zero as found for P450 Compound I oxidations of styrene [23], then the $\log A$ term in the Arrhenius kinetic expression is 13.1. Using this $\log A$ value and the observed rate constant of $k_{\mathrm{ox}}=0.30 \mathrm{~s}^{-1}$ at $-50{ }^{\circ} \mathrm{C}$, one estimates that $k_{\mathrm{OX}}$ will be about $600 \mathrm{~s}^{-1}$ at $22{ }^{\circ} \mathrm{C}$. The binding constant at room temperature is much more difficult to estimate, but a guess based on the results for styrene oxidations by photo-generated oxidants from $\mathrm{P} 450$ enzymes [23] would be that the value at $-50{ }^{\circ} \mathrm{C}\left(K_{\text {bind }}=\right.$ $3.8 \times 10^{4} \mathrm{M}^{-1}$ ) will decrease by about 2 orders of magnitude at $22^{\circ} \mathrm{C}$. If so, one predicts that the low temperature results for styrene oxidation by the photo-generated CPO oxidant would correspond to an apparent second-order rate constant at $22{ }^{\circ} \mathrm{C}$ on the order of $2 \times 10^{5} \mathrm{M}^{-1}$ $\mathrm{s}^{-1}$, which is slightly greater than the experimental value of $6 \times 10^{4} \mathrm{M}^{-1} \mathrm{~s}^{-1}$ found for CPO Compound I produced by chemical oxidation [10]. The estimated value obviously can have a large error, but the important point is that the reactivities of the chemically generated and photogenerated oxidants appear to be about the same.

One can also compare the kinetic results found here with those obtained for oxidation of styrene by the photo-generated oxidants from the $\mathrm{P} 450$ enzymes CYP119 and CYP102A1 $\mathrm{HD}$ [23]. The binding constants for the various Compounds I can be widely different, but the first-order oxidation rate constants should be similar. Indeed, the $k_{\mathrm{Ox}}$ values at $-50{ }^{\circ} \mathrm{C}$ are similar giving free energies of activation, $\Delta G^{\ddagger}$, of $13.4 \mathrm{kcal} / \mathrm{mol}$ (CPO oxidant), $13.9 \mathrm{kcal} / \mathrm{mol}$ (CYP119 oxidant), and $14.6 \mathrm{kcal} / \mathrm{mol}$ (CYP102A1 $1_{\mathrm{HD}}$ oxidant). Again, although it is interesting to note that the $\mathrm{CPO}$ oxidant is somewhat more reactive towards styrene than the oxidants prepared in the same manner from the two P450 enzymes, the more important observation is that the oxidation rate constants are similar for the three. The conclusion is that the photo-oxidation pathway is forming the same type of oxidant for CPO and P450 enzymes. 
In conclusion, the photo-oxidation route for production of Compounds I from heme enzymes was used to prepare a highly reactive CPO oxidant from irradiation of Compound II at low temperature. This transient was characterized by UV-visible and EPR spectroscopies and product and kinetic studies of styrene oxidations, and it was found to be similar in reactivity towards styrene as CPO Compound I formed by chemical oxidation and the P450 oxidants formed in the photo-oxidation pathway. The UV-visible spectra observed at low temperature do not contain the long wavelength Q-band absorbance ascribed to CPO Compound I formed by chemical oxidation of the enzyme, indicating that the species formed by photo-oxidation of CPO Compound II, although a strong oxidant, is not the same as CPO Compound I formed by chemical oxidation of the resting enzyme. The origin of the difference, whether resulting from conformational changes, changes in the favored electronic state, or differences in the identity of the organic radical, remains an intriguing question for further studies.

\section{Acknowledgments}

This work was supported by grants from the National Institutes of Health (GM-48722 to MN, GM-68621 to LWMF, and EB-001980 to the National Biomedical EPR Center, Medical College of Wisconsin).

\section{References}

1. Ortiz de Montellano, PR., editor. Cytochrome P450 Structure, Mechanism, and Biochemistry. 3rd ed.. New York: Kluwer Academic; 2005.

2. Denisov IG, Makris TM, Sligar SG, Schlichting I. Chem. Rev 2005;105:2253-2277. [PubMed: 15941214]

3. Mansuy D. Pure Appl. Chem 1994;66:737-744.

4. Groves, JT. Cytochrome P450 Structure, Mechanism, and Biochemistry, vol. Models and Mechanisms of Cytochrome P450 Action. Ortiz de Montellano, PR., editor. New York: Kluwer; 2005. p. 1-43.

5. Guengerich, FP.; Ortiz de Montellano, PR., editors. Cytochrome P450 Structure, Mechanism, and Biochemistry, vol. Human Cytochrome P450 Enzymes. New York: Kluwer; 2005. p. 377-530.

6. Nelson, DR. Cytochrome P450 Homepage. http://drnelson.uthsc.edu/cytochromeP450.html

7. Dolphin D, Forman A, Borg DC, Fajer J, Felton RH. Proc. Natl. Acad. Sci. U. S. A 1971;68:614-618. [PubMed: 5276770]

8. Morris DR, Hager LP. J. Biol. Chem 1966;241:1763-1768. [PubMed: 5949836]

9. Palcic MM, Rutter R, Araiso T, Hager LP, Dunford HB. Biochem. Biophys. Res. Commun 1980;94:1123-1127. [PubMed: 7190391]

10. Zhang R, Nagraj N, Lansakara DSP, Hager LP, Newcomb M. Org. Lett 2006;8:2731-2734. [PubMed: 16774243]

11. Araiso T, Rutter R, Palcic MM, Hager LP, Dunford HB. Can. J. Biochem 1981;59:233-236. [PubMed: 7195767]

12. Brill AS, Williams RJP. Biochem. J 1961;78:253-262. [PubMed: 16748874]

13. Makris TM, von Koenig K, Schlichting I, Sligar SG. J. Inorg. Biochem 2006;100:507-518. [PubMed: 16510191]

14. Zhang R, Chandrasena REP, Martinez E II, Horner JH, Newcomb M. Org. Lett 2005;7:1193-1195. [PubMed: 15760172]

15. Newcomb M, Zhang R, Chandrasena REP, Halgrimson JA, Horner JH, Makris TM, Sligar SG. J. Am. Chem. Soc 2006;128:4580-4581. [PubMed: 16594688]

16. Sheng X, Horner JH, Newcomb M. J. Am. Chem. Soc 2008;130:13310-13320. [PubMed: 18788736]

17. Sheng X, Zhang HM, Im SC, Horner JH, Waskell L, Hollenberg PF, Newcomb M. J. Am. Chem. Soc 2009;131:2971-2976. [PubMed: 19209859]

18. Daiber A, Herold S, Schöneich C, Namgaladze D, Peterson JA, Ullrich V. Eur. J. Biochem 2000;267:6729-6739. [PubMed: 11082183]

19. Gebicka L, Didik J. J. Inorg. Biochem 2007;101:159-164. [PubMed: 17056120]

20. Hollenberg PF, Hager LP. Meth. Enzymol 1978;52:521-529. [PubMed: 566840] 
21. Hashimoto A, Pickard MA. J. Gen. Microbiol 1984;130:2051-2058.

22. Hager LP, Morris DR, Brown FS, Eberwein H. J. Biol. Chem 1966;241:1769-1777. [PubMed: 5945851]

23. Yuan X, Wang Q, Horner JH, Sheng X, Newcomb M. Biochemistry 2009;48:9140-9146. [PubMed: 19708688]

24. Uppu RM, Pryor WA. Anal. Biochem 1996;236:242-249.

25. Wang Q, Sheng X, Horner JH, Newcomb M. J. Am. Chem. Soc 2009;131:10629-10636. [PubMed: 19572732]

26. Green MT, Dawson JH, Gray HB. Science 2004;304:1653-1656. [PubMed: 15192224]

27. Newcomb M, Halgrimson JA, Horner JH, Wasinger EC, Chen LX, Sligar SG. Proc. Natl. Acad. Sci. U.S.A 2008;105:8179-8184. [PubMed: 18174331]

28. Nakajima R, Yamazaki I, Griffin BW. Biochem. Biophys. Res. Commun 1985;128:1-6. [PubMed: 3985960]

29. Rutter R, Hager LP. J. Biol. Chem 1982;257:7958-7961. [PubMed: 6282864]

30. Rutter R, Hager LP, Dhonau H, Hendrich M, Valentine M, Debrunner P. Biochemistry 1984;23:68096816. [PubMed: 6099143]

31. Hollenberg PF, Hager LP, Blumberg WE, Peisach J. J. Biol. Chem 1980;255:4801-4807. [PubMed: 6246083]

32. Jung C, Schunemann V, Lendzian F, Trautwein AX, Contzen J, Galander M, Bottger LH, Richter M, Barra AL. Biol. Chem 2005;386:1043-1053. [PubMed: 16218876]

33. Daiber A, Bachschmid M, Beckman JS, Munzel T, Ullrich V. Biochem. Biophys. Res. Commun 2004;317:873-881. [PubMed: 15081421]

34. Blanke SR, Martinis SA, Sligar SG, Hager LP, Rux JJ, Dawson JH. Biochemistry 1996;35:1453714543. [PubMed: 8931550]

35. Blumberg WE, Peisach J, Wittenberg BA, Wittenberg JB. J. Biol. Chem 1968;243:1854-1862. [PubMed: 5646479]

36. Rutter R, Valentine M, Hendrich MP, Hager LP, Debrunner PG. Biochemistry 1983;22:4769-4774. [PubMed: 6313048]

37. Roberts JE, Hoffman BM, Rutter R, Hager LP. J. Biol. Chem 1981;256:2118-2121. [PubMed: 6257699]

38. Benecky MJ, Frew JE, Scowen N, Jones P, Hoffman BM. Biochemistry 1993;32:11929-11933. [PubMed: 8218266]

39. Takahashi A, Ohba Y, Yamauchi S, Fujii H. Chem. Lett 2009;38:68-69.

J Inorg Biochem. Author manuscript; available in PMC 2011 November 1. 


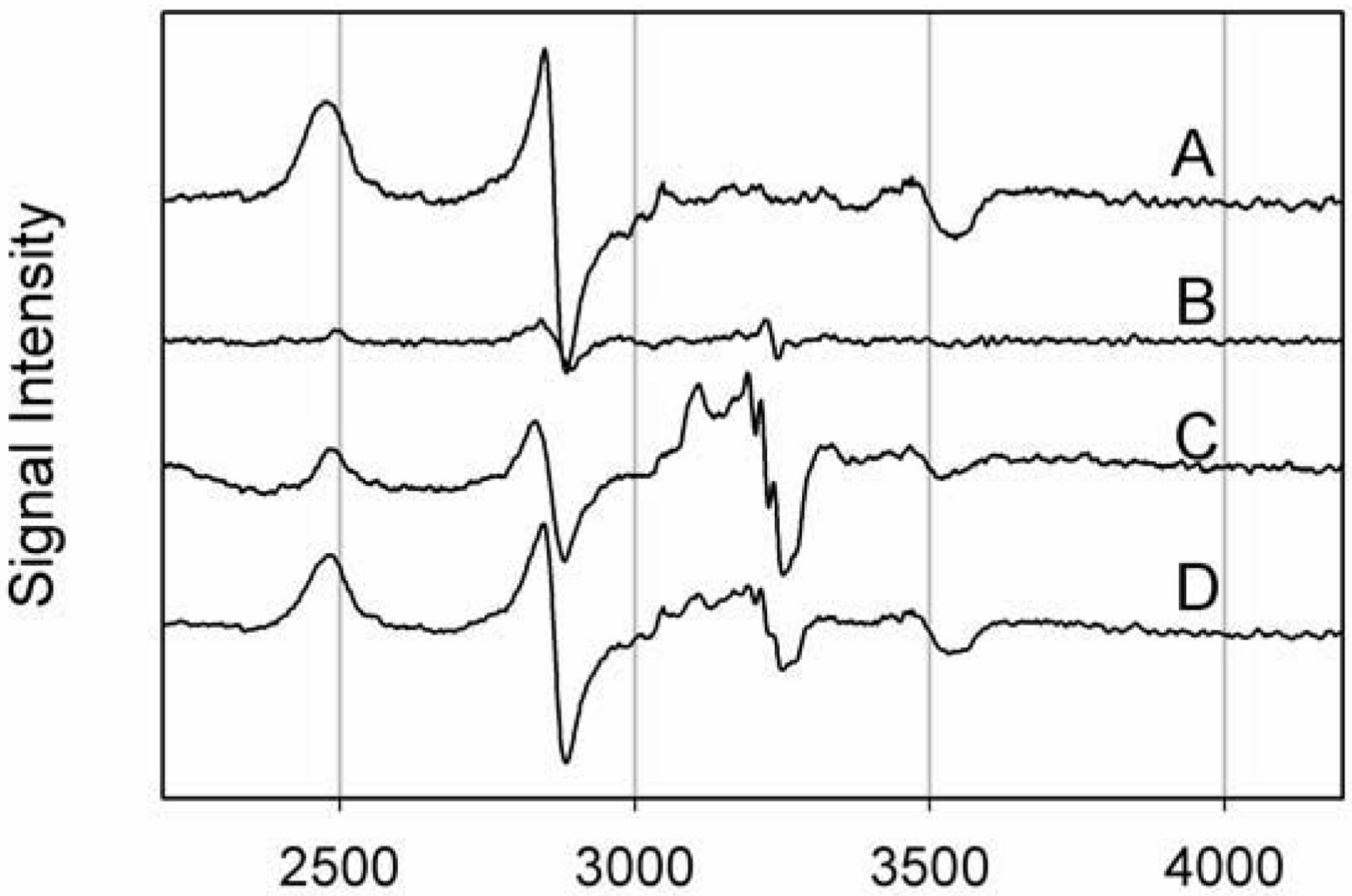

\section{Gauss}

Figure 1.

EPR spectra of CPO at 77 K. (A) Resting enzyme. (B) After treatment with PN. (C) After photolysis at $-45^{\circ} \mathrm{C}$ in the absence of substrate. (D) After photolysis at $-45^{\circ} \mathrm{C}$ in the presence of $0.1 \mathrm{mM}$ styrene. 


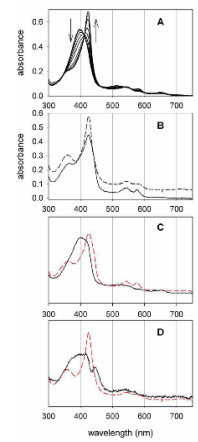

Figure 2.

UV-visible spectra. (A) High-spin CPO converting to low-spin as a sample cools from 22 to $-45^{\circ} \mathrm{C}$. (B) Observed spectra following irradiation of CPO Compound II at $-50{ }^{\circ} \mathrm{C}$ in the absence (solid line) and presence (dashed line) of $0.5 \mathrm{mM}$ styrene. (C) Deconvoluted spectra from reaction following irradiation of CPO Compound II at $-50{ }^{\circ} \mathrm{C}$ in the absence of substrate. (D) Deconvoluted spectra from reaction following irradiation of CPO Compound II at $-50^{\circ}$ $\mathrm{C}$ in the presence of $0.5 \mathrm{mM}$ styrene. In spectra $\mathrm{C}$ and $\mathrm{D}$, species $\mathrm{A}$ is the solid black line, and species B is the dashed red line (see text). 


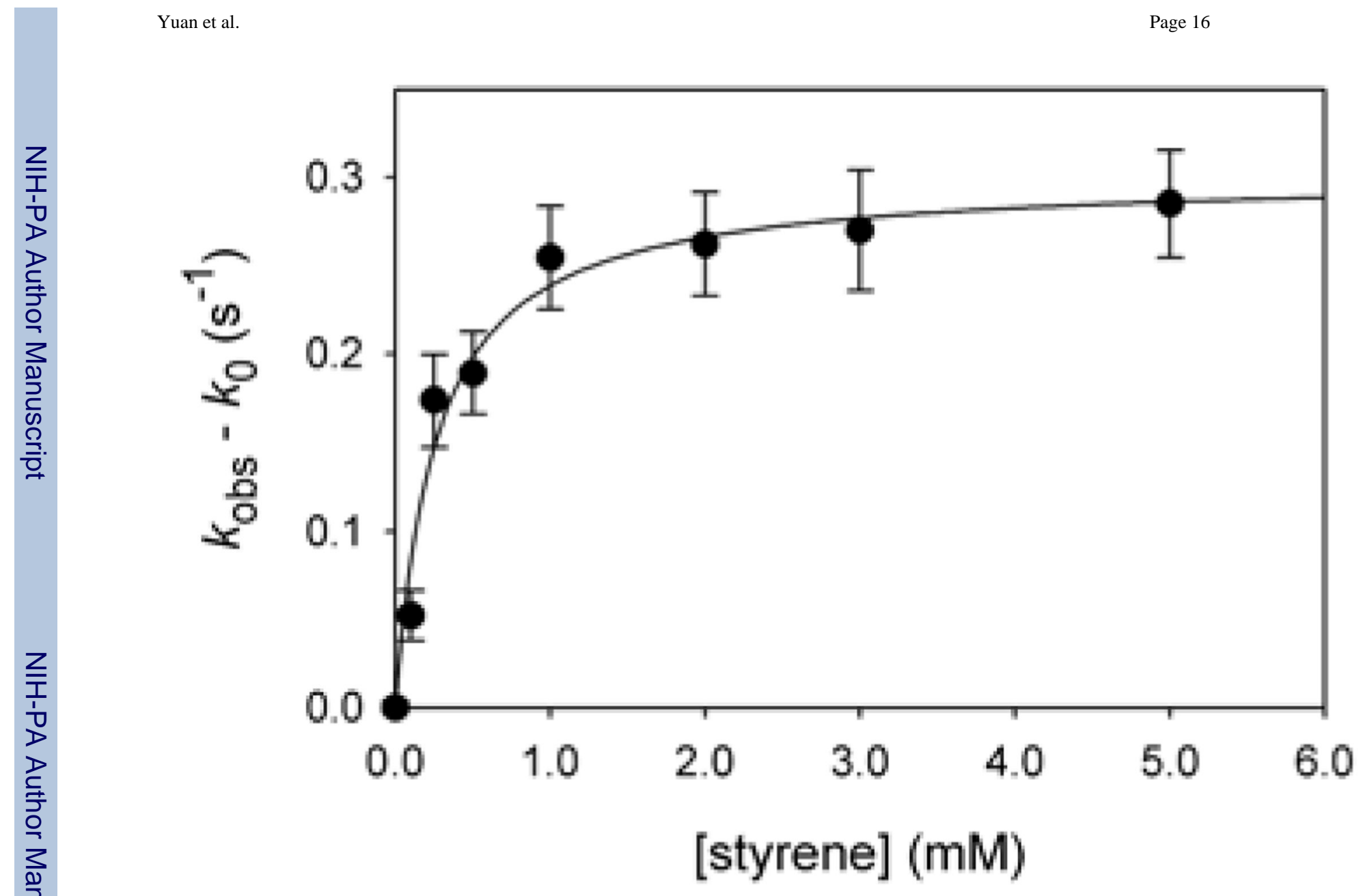

Figure 3.

Kinetic results for oxidation of styrene at $-50^{\circ} \mathrm{C}$. The error bars for the observed kinetic values are at $1 \sigma$. The fitting line was calculated from the values of $K_{\text {bind }}$ and $k_{\text {ox }}$ given in the text. 


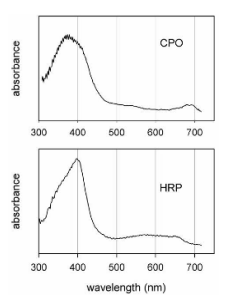

Figure 4.

UV-visible spectra of Compounds I obtained in stopped-flow studies at room temperature. CPO Compound I was from oxidation of the enzyme with peroxyacetic acid at $\mathrm{pH} \approx 4$. Horseradish peroxidase (HRP) Compound I was from oxidation of the enzyme with hydrogen peroxide at $\mathrm{pH} \approx 7$. 


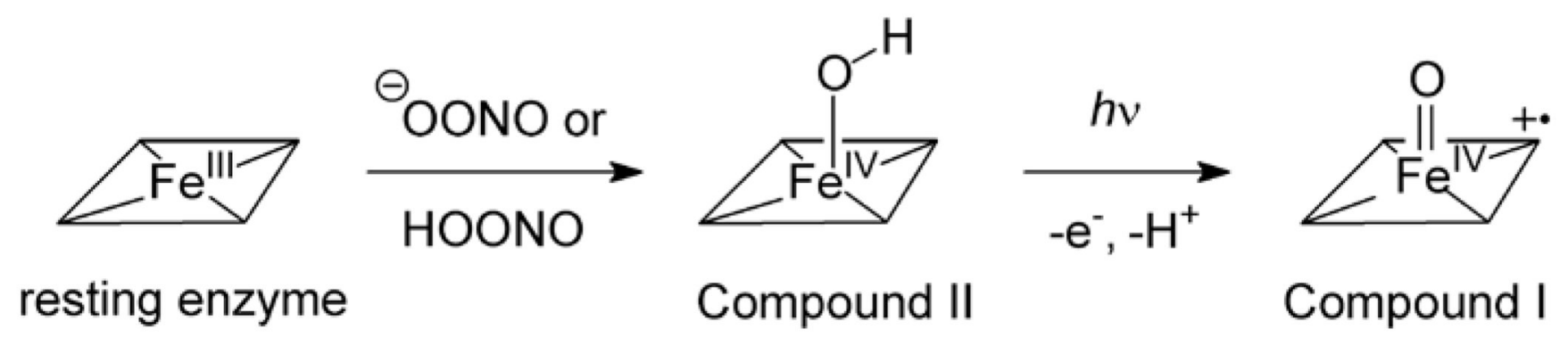

Scheme 1. 


\section{$K_{\text {bind }}$ \\ $k_{\mathrm{ox}}$ \\ $\mathrm{E}^{*}+\mathrm{Sub}$

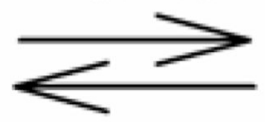 \\ $E^{*} S$ \\ $E+F$}

Scheme 2. 


\section{Table 1}

Results of chlorodimedone assays of $\mathrm{CPO}^{a}$

\begin{tabular}{|c|c|c|}
\hline Sample $^{a}$ & Volume $(\mu \mathrm{L})^{b}$ & Velocity $\times 100\left(\mathrm{AU} \mathrm{s}^{-1}\right)^{c}$ \\
\hline \multirow[t]{4}{*}{$1 \mathrm{a}$} & 10 & 0.46 \\
\hline & 20 & 0.85 \\
\hline & 30 & 1.25 \\
\hline & 40 & 1.75 \\
\hline \multirow[t]{4}{*}{$1 b$} & 10 & 0.50 \\
\hline & 20 & 0.69 \\
\hline & 30 & 1.45 \\
\hline & 40 & 1.65 \\
\hline \multirow[t]{3}{*}{$1 \mathrm{c}$} & 20 & 0.68 \\
\hline & 30 & 1.15 \\
\hline & 40 & 1.85 \\
\hline \multirow[t]{4}{*}{$2 a$} & 10 & 0.57 \\
\hline & 20 & 1.05 \\
\hline & 30 & 1.65 \\
\hline & 40 & 2.45 \\
\hline \multirow[t]{4}{*}{$2 b$} & 10 & 0.47 \\
\hline & 20 & 1.15 \\
\hline & 30 & 2.15 \\
\hline & 40 & 3.25 \\
\hline
\end{tabular}

${ }^{a}$ Samples 1a and 2a were reference samples; sample $\mathbf{1 b}$ was treated with 65 equivalents of $\mathrm{PN}$ at $-15^{\circ} \mathrm{C}$; sample $\mathbf{1} \mathbf{c}$ was treated with 650 equivalents of PN at $-15^{\circ} \mathrm{C}$; sample $2 \mathbf{b}$ contained $0.5 \mathrm{mM}$ styrene and was treated with 75 equivalents of $\mathrm{PN}$ at $-15^{\circ} \mathrm{C}$, cooled to $-50{ }^{\circ} \mathrm{C}$ and irradiated with 360 nm light.

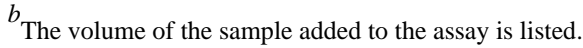

${ }^{c}$ Observed velocity minus background velocity in the absence of CPO. 